Slices of meaning : Levels of analysis and the unity of understanding

Riegelnik, Stefan

Posted at the Zurich Open Repository and Archive, University of Zurich ZORA URL: https://doi.org/10.5167/uzh-143107

Book Section

Published Version

Originally published at:

Riegelnik, Stefan (2017). Slices of meaning : Levels of analysis and the unity of understanding. In: Conrad, Sarah-Jane; Petrus, Klaus. Meaning, Context and Methodology. Berlin: De Gruyter, 213-226. 


\title{
Slices of meaning: Levels of analysis and the unity of understanding
}

\begin{abstract}
Although there is little agreement about where the demarcation line between semantics and pragmatics lies, there is strong consensus that those who ignore or deny the distinction are on a wrong track. In this paper I do not want to provide a further suggestion on how to make the distinction. Instead, I want to raise a problem for any theory of language based on a distinction between semantics and pragmatics. I argue that the idea of decomposing an utterance into a semantic and a pragmatic part precludes an account of the unity an utterance exhibits. For this reason, I conclude that approaches towards a theory of language based on a distinction between semantics and pragmatics should be reconsidered.
\end{abstract}

\section{Introduction}

Philosophers and linguists of many persuasions appeal to the distinction between semantics and pragmatics. Their motives for introducing the distinction are legion (Morris 1938, Austin 1962, Levinson 1983, Stalnaker 1970, Grice 1989, Bach 2004) and so are the views on its nature. Broadly speaking, and from an uncritical perspective, the distinction is a way to differentiate elements and effects as constituents of an arbitrary utterance. I assume that an utterance is the primary unit of meaning and that meaning and interpretation are deeply linked. ${ }^{1}$ Granting these assumptions, the distinction between semantics and pragmatics might be understood as a way to decompose natural language utterances. By way of an example, imagine the utterance of "This is Ginger" where the speaker points to a specific person standing in the corner. With the help of the gesture an interpreter is able to recognise what the speaker intends to say by using the words "This", "is" and "Ginger" and the pointing at the specific person. Decomposing the utterance into the words chosen by the speaker and the speaker's gesture, the study of the meaning of the words, or their literal meaning, or what Grice identifies as the conventional meaning (Grice 1988: 25) falls within the scope of

1 Some readers might find this counterintuitive; to belie these worries, see Davidson 1967 and 1970. 
semantics. All further factors pertaining to the utterance, such as the gesture, belong to the study of pragmatics. The former is often considered to be the study of the context-invariant meaning; the latter is often considered to be the study of what is conveyed in a particular context. But wherever one draws the line between semantics and pragmatics, it appears to be plausible to understand the interpretation of the utterance as an interplay between elements and effects pertaining to both realms. For imagine the situation without the speaker's gesture: then the interpreter might have taken the speaker to say something quite differently. For example, the speaker might be pointing out that the odd flavour of the wine is caused by ginger. Or, imagine that the speaker uses different words, say, "I”, “am” and “Ginger”.

In this paper I am not concerned with the question of where philosophers and linguists should draw a line between semantics and pragmatics. Instead, I want to concentrate on the question of how these elements and effects are to be related so that an utterance emerges. For my purpose it is thus of secondary importance where or how the line is drawn, as long as there is a one. I am considering any theory of interpretation that asserts a semantics-pragmatics distinction regardless of how it further articulates that distinction. Then, by assumption, any of these theories must provide some account of how pragmatic and semantic elements within a given utterance come together so that a unified whole emerges. Because it is in virtue of this unity that an utterance could be judged to be either true or false, or, appropriate or inappropriate. Consider again the "This is Ginger"-utterance: Both the gesture and the words are supposed to belong to the utterance and both are relevant for its interpretation. If so, then merely listing the constituting parts will not suffice to explain the interplay between semantics and pragmatics. For what needs to be accounted for is the unity the "This-is-Ginger"utterance exhibits.

In what follows, I argue that it is precisely the requirement for the unity of an utterance that represents a stumbling block for theorists building frameworks predicated on the semantic-pragmatic distinction. In the context of the debate about the unity the way an utterance gets decomposed is of crucial importance. Thus even if one assumes that one can safely ignore the unity problem when it arises in the context of the debate about the semantics-pragmatics distinction, one can insist that the decomposition of an utterance results in elements which could be reunified in principle. This I take it to be a minimal condition for any theory of meaning. ${ }^{2}$ For, prima facie, if this condition is not met, one does not

2 I follow the truism that to understand an utterance is to know what it means. Thence a theory of meaning is on a par with a theory of interpretation. 
know how linguistic decomposition relates to the utterance. As I argue, the idea of dividing an utterance into a semantic part and a pragmatic part conflicts with the minimal condition. ${ }^{3}$

The structure of my paper is as follows: In the subsequent section, I discuss the idea and some of the motives behind the distinction of the semantics and the pragmatics of an utterance. In section 3, I formulate by means of Russell's analysis of propositions the problem of the unity of the utterance. As a point of reference, in section 4 I discuss briefly Davidson's solution to this problem and his understanding of the semantics of a declarative sentence. In the last sections I focus on so-called near-side pragmatic effects in their alleged function to codetermine the truth conditions of an utterance. I take near-side pragmatic effects as an example because they display the required unity clearly. However, I think the scope of the problem is greater than the examples I discuss. In conclude that theories based on a distinction between semantics and pragmatics face a fatal problem when it comes to explaining the unity of an utterance.

\section{In slices - ways to decompose an utterance}

Ever since the publication of Charles Morris' Foundations of a Theory of Signs (1938) and the introduction of the trichotomy between syntax, semantics and pragmatics, philosophers of language and linguists have quarreled over the question of where to draw a line between these three realms. Traditionally, syntax and semantics deal with the context-invariant aspects of an utterance and pragmatics deals with the context-dependent ones. Accordingly, various utterances of the sentence-type "This is Ginger" share as the context-invariant part the sentence, irrespective of what the demonstrative "this" refers to. However, drawing the line in this way is now considered to be inadequate - for it is too simplistic (cf. Stanley 2007: 32). In the wake of H.P. Grice's distinction between what is said and what is implicated by an utterance, the debate on what pertains to semantics and what to pragmatics has received a considerable boost. ${ }^{4}$ Attempting to develop a more sophisticated theory, Grice divides the interpretation of an utterances into two phases. The first one deals with truth conditions of an uttered sentence and results in what is said (Grice 1989: 25). This phase rests heavily on conventionally

3 See Hylton (1984) and Gaskin (2008) who stress the relevance of the problem of the unity.

4 Grice did not make use of the expressions "semantics" and "pragmatics". He pointed out that his use of "say" and "what is said" or "implicate" or "what is implicated" deviate from ordinary usage (Grice 1988: 25). 
encoded sentence or word meaning and includes the assignment of denotations of the words (including indexical expressions) and their combination. The second phase takes as input that what is said and deals with everything else that is conveyed with an utterance. It runs along general conversational principles which enable the interpreter to infer what the speaker implicates.

Although there is consensus that Grice's model needs to be refined in several respects, his model still plays an important role in contemporary debates on the distinction between semantics and pragmatics. Most notably, contextualists of various manifestations argue that what is said with an utterance is influenced to a far larger extent by near-side pragmatic effects than Grice allows (Recanati 2001, 2004, 2010; Stanley 2007; Cappelen/Lepore 2005).

Accordingly, contemporary contextualists' theories of interpretation can be grouped by the degree of impact of pragmatic effects on truth conditions, i.e. by the number of assumed context-sensitive expressions.

In contrast to the wide ranging and acrimonious discussions on the nature of the distinction, skeptical doubts concerning the viability of a distinction between semantics and pragmatics have been mostly neglected. ${ }^{5}$ The fundamental questions to be addressed are: Are natural languages suitable for such a distinction at all? Is it possible to draw a sharp line? Would it be better if philosophers and linguists gave up the quest for a demarcation line altogether?

Kent Bach is among those philosophers and linguists for whom the answer to the first two questions is clearly "yes". According to him, the reason for introducing the distinction is "to provide a framework for explaining the variety of ways in which what a speaker conveys can fail to be fully determined by the (conventional) linguistic meaning of the sentence he utters" (Bach 1999: 66). Bach cites indexicality, ambiguity, vagueness, semantic underdetermination, implicitness, implicature, and non-truth-conditional content as linguistic phenomena that require the introduction of a framework with different levels or slices. The framework he has in mind is supposed to cover the differences in the explanatory functions. Consider again an utterance of "This is Ginger". ${ }^{6}$ Understanding the word meaning of "This", "is", and "Ginger" - usually considered to be the semantic part of an utterance and determined conventionally - would not suffice to understand what a speaker conveys by this utterance. Even if one consulted a myriad of dictionaries, one would not find an answer to the question of what the demonstrative "this"

5 A dissenting voice is Cappelen (2007).

6 In what follows, I focus on the demonstrative "this", but the same line of reasoning would apply to other expressions taken to be context-sensitive. 
used as part of a particular utterance refers to. So it appears to be the defining feature of utterances in which "this" is used that their meaning is different from context to context. This would make it plausible to think of the context of an utterance as what one ought to consider in order to understand an utterance containing "this". To be more precise, since the reference of the word "this" vary with the context, it seems to be plausible to say that the truth conditions are co-determined by the context. Thus the appeal to the context of an utterance looks not only to be innocuous, but positively necessary in order to determine the meaning of an utterance of a sentence containing an indexical expression or a demonstrative.

In contemporary debates on the role of an utterance's context, minimalists (Cappelen/Lepore 2005, Borg 2004) claim that, basically, near-side pragmatic effects with regard to indexical expressions and demonstratives are relevant in order to determine what is semantically expressed. Moderate contextualists (Stanley 2007) agree with minimalists about this, but they also think that the class of expressions which are context-sensitive needs to be extended. Thus minimalists seek to confine near-side pragmatic effects to a very small class of expressions, whereas moderate contextualists are open to extending the class of contextsensitive expression. In contrast to the two aforementioned positions, radical contextualists (Recanati 2004, 2010, Bezuidenhout 2002) claim that near-side pragmatic effects are required for the emergence of a truth-evaluable entity even if the sentence does not contain any obvious context-sensitive expressions. They further claim that these effects cannot be confined to a specific class of expressions. The role of the semantical level of a framework is understood as that of a potentiality. For expressions are not considered to be meaningful independently of a speech act (Recanati 2004: 152). In any case, the boundary between semantics and pragmatics seems to be blurred. But in all three positions outlined above there is agreement that pragmatic effects determine to at least some degree the truth conditions of an utterance. In contrast to them, Bach insists that "semantics and pragmatics have distinct subject matters, sentences and utterances, respectively" (Bach 2004: 28). He maintains that we are able to draw a clear-cut line between these areas. For him "semantic properties are on a par with syntactic and phonological properties: they are linguistic properties. Pragmatic properties, on the other hand, belong to acts of uttering sentences in the course of communicating" (Bach 2004: 24). I quote some further philosophers and linguists to show that Bach is not alone in this view:

The fact that a word or phrase has a certain meaning clearly belongs to semantics. On the other hand, a claim about the basis for ascribing a certain meaning to a word or phrase does not belong to semantics. (Almog/Wettstein/Kaplan 1989: 573)

[...] traditionally, [...] semantics [is] to be the study of meaning, [...] pragmatics is the study of language usage. (Levinson 1983: 5) 
A strong pragmatic effect on what is communicated is one in which context affects what is communicated, but not by affecting the referential contents of any lexical item in a sentence. (Stanley/King 2005: 140)

If one understands the distinction as clear-cut as stated explicitly by Bach, one might wonder why semantics and pragmatics are mentioned in the same breath at all. Put differently, if despite their "distinct subject matters" (Bach 2004: 28) both semantics and pragmatics belong somehow together, the assumed substantial relation between them needs to be accounted for. Or, if one admits that the distinction is as explicit and as clear-cut as suggested by Bach and also thinks that there is no substantial relation between semantics and pragmatics, then, admittedly, one does not need to provide an account of the relationship between these fields, i.e. the unity of the utterance. But then the motives for the debate about the distinction become even less comprehensible. For on Bach's model, why should we understand pragmatics as being part of linguistics at all?

In contrast to the philosophers and linguists I have just quoted, I hold that to account for the distinction between semantics and pragmatics requires one to understand these aspects as being mutually dependent. Intuitively, if one maintains that there is a distinction, one should be able to account for each of the aspects independently of the others. However, this seems to be deeply problematic as near-pragmatic effects show. So what I claim is that the identification of semantic properties is dependent on appealing to pragmatic aspects - and vice versa. Consequently, it is a mistake to study semantic or pragmatic elements and effects in isolation. This can be shown by the inability of advocates of such a distinction to meet the requirement I call the independency condition: the appeal to semantic or pragmatic properties has to make sense independently of other factors or levels of a framework built to explain the interpretation of an utterance. That this is the aim of proponents of a semantic-pragmatic distinction is shown by the above mentioned quotes where the possibility of the study of semantic and pragmatic entities and effects is assumed. However, as I argue in the remainder of this paper, the independent study of semantic and pragmatic elements and effects falls prey to the same problem that has plagued philosophers when it comes to account for the unity of the proposition.

\section{The problem of the unity}

The problem of the unity of the propositions or the unity problem can be traced back to Plato and is addressed by philosophers in different areas. Nowadays, the problem is understood mostly as pertaining to the philosophy of language. 
It emerges when we ask how singular terms are related to predicates so that one gets a unified sentence or proposition. I rephrase this question in the light of the debate on the distinction between semantics and pragmatics: how are elements and effects pertaining to either of these realms merged so that one gets a unified utterance? In order to demonstrate the pertinence of the unity problem for the debates on a distinction between semantics and pragmatics, I refer to Russell's analysis of a proposition. I then show how, mutatis mutandis, the same problem besets the distinction between semantics and pragmatics.

In dealing with the nature of the special unity of a proposition, Russell writes in the Principles of Mathematics:

Consider, for example, the proposition "A differs from B". The constituents of this proposition, if we analyse it, appear to be only A, difference, B. Yet these constituents, thus placed side by side, do not reconstitute the proposition. The difference which occurs in the proposition actually relates $\mathrm{A}$ and $\mathrm{B}$, whereas the difference after analysis is a notion which has no connection with A and B. It may be said that we ought, in the analysis, to mention the relations which difference has to $A$ and $B$, relations which are expressed by is and from when we say "A is different from B". These relations consist in the fact that $A$ is referent and $B$ relatum with respect to difference. But "A, referent, difference, relatum, B" is still merely a list of terms, not a proposition. A proposition, in fact, is essentially a unity, and when analysis has destroyed the unity, no enumeration of constituents will restore the proposition. The verb, when used as a verb, embodies the unity of the proposition, and is thus distinguishable from the verb considered as a term, though I do not know how to give a clear account of the precise nature of the distinction. (Russell [1903] 2010: §54)

As Russell writes, under analysis a proposition loses its unity. Part of the analysis of a proposition is that we decompose it into its constituents. What, then, needs to be accounted for is the unity a proposition exhibits. One should not be puzzled by Russell's realist view of propositions and what their constituents are, for at least in this context it is secondary what one takes to be the primary unit of meaning Russellian propositions, sentences, utterances etc. Regardless which of them is considered to be the primary unit of interpretation, when analysing it, i.e. decomposing it into its constituents, one "destroys" its unity: one gets a mere list of constituents. However, an utterance or a proposition differs fundamentally from such a list. In contrast to a list, an utterance as the primary bearer of meaning can be, most strikingly, either true or false, or, appropriate or inappropriate. Only in virtue of a unity these predicates can be ascribed to an utterance. ${ }^{7}$

7 For contemporary contributions and the different presentations of the problem, see Davidson (2005), Gaskin (2008), contributions to Riegelnik (2010). 
If - as Russell anticipates - one tries to achieve the restoration of the unity by appeal to a relation, perhaps referred to by the copula, one will be disappointed. The so introduced relation is but a further element on the list of unjoined parts and there is still no unity between them in sight which could be true or false, appropriate or inappropriate. Further, for reasons of consistency, another relation needs to be introduced which is supposed to unite the original list of components with the initially introduced relation. But again, this relation is just a further item on the list of unjoined parts. And so forth, ad infinitum. This shows that the appeal to relations in order to restore the unity is a hopeless endeavour, for it ends in an inescapable infinite regress. It is not the nature of a relation that causes the regress - whatever entity or means one introduces as a form of "glue" in order to combine the components, one ends up in the regress just sketched. ${ }^{8}$

Russell discusses the problem of the unity of the proposition in the light of the debate on the semantic role of verbs or predicates: for him a theory of predication is supposed to explain the unity. He does not have the distinction between semantics and pragmatics in mind. However, the same problem emerges when we attempt to account for the relationship between semantic and pragmatic entities and effects.

An utterance, taken as the primary unit of meaning or interpretation, is considered to comprise all elements and effects relevant for its constitution. An advocate of a distinction between the semantics and the pragmatics of an utterance might analyse the "This-is-Ginger"-utterance as follows: it consists, on the one hand, of the expressions used and, on the other hand, the part which is conveyed by pointing towards Ginger, and perhaps also further factors which need not concern us here. The choice of words and the way these words are uttered determine ideally in a decisive way the interpretation of the utterance. Counterfactually, the interpretation of the utterance would differ, if the speaker acted in a different way or if she used different words. Imagine if the speaker is sipping her wine, one can assume "ginger" in "This is ginger" refers to a spice. Conversely, she may say "This woman in the corner with the nice coat is Ginger" and, clearly, "this" refers to the woman named Ginger. But in virtue of what do the expressions and the gesture form a unity? As Russell's analysis of a proposition shows, as soon as one needs to account for a combination of these parts, be it thought as the combination of the context-independent part with the context-dependent one, or the gesture and the words, the analysis is threatened by an infinite regress. For

8 Showing how prominent accounts fall into this trap is Davidson's leitmotif in Truth and Predication (2005). 
then one would need a further entity which unites the unifying entity with the original parts. So we are left with distinct entities.

\section{Truth-conditional semantics and the unity of the sentence}

In contrast to contemporary truth conditional theories of meaning such as minimalism, moderate contextualism or radical contextualism, in Davidson's account of the semantics of a declarative sentence one does not find a distinction between semantics and pragmatics. One could even sum up Davidson's approach by emphasizing that any independent specification of truth conditions, or the supposed to be semantic meaning as independent from pragmatics, or the meaning of a predicate expression as independent from the meaning of the utterance etc. is utterly mistaken. For, by Davidson's lights, such a distinction makes it impossible to understand how expressions are used as part of a sentence in such a way that one understands what somebody says (Davidson 1967: 17, 2005).

Whether or not one holds Davidson's approach towards a unified theory of meaning viable, it serves as a point of reference for the question of the unity of semantics and pragmatics. In Truth and Predication (2005) Davidson follows Russell in discussing the problem of the unity of a proposition in connection with the problem of predication. Davidson argues that the semantic role of a predicate cannot be explained unless we examine it in the context of a whole sentence. His solution to the unity problem is part of his comprehensive theory of meaning in which the principle of compositionality plays a key role. According to this principle, the meaning of complex meaningful expressions, i.e. sentences, is considered to be determined of the meaning of simpler expressions. The question now is: what concepts should one appeal to if one wants to explain the contribution of the parts of a sentence? In the case of a subject - usually a singular term - the concept philosophers appeal to is reference or denotation. But what concept one should appeal to if one wants to explain the contribution of the predicate? In order to determine the predicate's contribution to the truth conditions, Davidson appeals to the concept of satisfaction: it pairs objects with so-called open sentences, which are expressions with free variables. An object satisfies an open sentence if the resulting sentence is true. Hence snow satisfies " $\mathrm{x}$ is white", for "snow is white" is true and grass does not satisfy " $\mathrm{x}$ is white" for it is not the case that grass is white. The approach just sketched emerges from Davidson's engagement with accounts that could not properly explain the unity of the utterance. Pursuant to this, Davidson's own account is not subject to these deficiencies (cf. Davidson 2005: chapter 7). Most essentially, 
it does not generate an infinite regress and it links predicates as essential parts of sentences to the sentences' truth conditions. "In a minimal but important respect", Davidson states, "a theory of truth for a language does [...] what we want, that is, give the meaning of all independently meaningful expressions on the basis of an analysis of their structure" (Davidson 1970: 55). The structure, as I have already pointed out, must not be understood as being independent of the utterance or as an additional part in the way Russell had thought of it in his multiple relation theory.

In Davidson one does not find a distinction between semantics and pragmatics, or, generally speaking, the idea of different levels. Nor does one find a distinction between sentences and propositions, the latter expressed by the former relative to different contexts, influenced and shaped by pragmatic effects. This, of course, does not mean that Davidson denies that factors usually grouped under the label pragmatics are relevant for the interpretation of an utterance. It is rather the idea of a "framework with different levels" (see section 2) that stands in opposition to his idea of a sound theory of interpretation. Also, interestingly, many contextualists who advocate a distinction between semantics and pragmatics see themselves as being in opposition to Davidson - as stated explicitly by Bezuidenhout - "[i]f one embraces the contextualist perspective one must give up traditional Davidsonian style semantic theories" (Bezuidenhout 2002: 105) - then because their emphasis on the significance of pragmatics is a view which would be for Davidson a version of reductionism. This is so because according to Davidson, contextualists try to save a distinction between semantics and pragmatics by negating one part of the assumed relation. In Davidson's model, ironically, defenders of the distinction end up trying to reduce one part of the distinction to the other.

\section{Near-side pragmatic effects and the unity of semantics and pragmatics}

As I have already pointed out, in recent years debates on the semanticspragmatics distinction have centred on the question of the degree of the impact of pragmatic effects or contextual contributions on the truth conditions of an utterance. This has led to considerations about the interplay between semantics and pragmatics given that it is assumed that a sentence might express different propositions relative to different contexts. ${ }^{9}$ The thesis I am going to scrutinize is

9 An argument along similar lines can be formulated for theories understanding the process of interpretation in two or more phases - for what unites the phases? 
that near-side pragmatic effects explain the divergence of sentence meaning and propositions expressed by sentences. In contrast to far-side pragmatic effects, near-side pragmatic effects are considered to be relevant for the determination of what is said (Grice 1989: 25) with the utterance of a sentence. This class of pragmatic effects - mostly contextual factors - comes into play when the knowledge of the sentence meaning is considered to be insufficient for the interpretation of an utterance. ${ }^{10}$ Since what is said with an utterance is usually associated with the truth-conditional meaning of an utterance, the governing assumption is that near-side pragmatic effects influence the determination of truth conditions of an utterance. Further it is assumed that these effects complement or modify the sentence meaning of the expressions or the semantic potentials used so that a truthevaluable entity - usually a proposition - results. Put this way, a proposition would be the result of a sentence enriched by near-side pragmatic effects. Intuitively, this seems to be correct, for one and the same sentence can be used to express different propositions. Again, the sentence "This is Ginger" uttered on different occasions can express different propositions, depending on the gesture, or more precisely, the person or the object "this" refers to. This requires that expressions composing a sentence have to be receptive to pragmatic effects: "this" must be understood as an expression being able to make varying contributions to the proposition expressed. If this were not the case, the proposition would be determined exclusively by the expressions used. Consequently, there would be no room for near-side pragmatic effects to determine or shape the proposition expressed by an utterance. However, the traditional way to cope with indexical expressions and demonstratives has on closer examination serious shortcomings.

My main objection is that such an approach faces the same dilemma which I stated implicitly before: either near-side pragmatic effects are tied to what is considered to be the semantic level of an utterance in a way that there is no distinction between semantics and pragmatics, or, there is a distinction, but the grounds for understanding this interplay remain opaque.

According to the first horn of the dilemma - near-side pragmatic effects must be tied to the semantic level, otherwise there is no mutual influence. And if there is no mutual influence, one can hardly speak of near-side pragmatic effects, for these effects are introduced precisely to influence the semantics of an utterance. For the sake of the argument, near-side pragmatic effects affect truth conditions via the expressions composing the sentence. They enrich or modulate the word meanings of the expressions composing the sentence. This entails that the expressions used have to be understood as incomplete. For if they were complete, near-side

10 This holds also for implicatures. 
pragmatic effects could not perform their function and enrich or modulate the word meanings. In other words, the incomplete part of the expression remains constant and gets completed or enriched from utterance to utterance or from context to context. This puts the semantic part of an utterance on a par with what Recanati calls "semantic potentials" (Recanati 2004: 152). Semantic potentials are taken to be the most basic unit. Above them, it is assumed that pragmatic effects are added at this higher level to supplement the semantics. Finally, the unity of these two levels is reflected by the utterance itself. However, this approach simply shifts the problem to the lower level. On the lower level, the same basic problem emerges. To wit, one still needs to account for how indexical expressions and demonstratives are open to pragmatic effects. In order to illustrate the point further, I return to Recanati's notion of semantic potentials - assuming that the level of semantic potentials does contribute to the higher level. But for this, a third factor is required relative to which varying contributions are made by one and the same semantic potential. The third factor could be thought again as near-side pragmatic effects - except that in this case they are supposed to be decisive for the contribution a semantic potential actually makes to the determination of the expressions which determine the next level, i.e. the proposition. Further if one now considers the semantic potential as part of the framework, i.e. as a level of the framework, one encounters the same problem again: one part of the semantic potential remains constant across different utterances and one part makes varying contributions. But where should one now tie the near-side pragmatic effects relative to which a contribution to the expression is made? Again we might introduce one further level, a potential of the semantic potential, and so on, ad infinitum. One gets again caught in an infinite regress. In summation, I conclude that either we assume that the meaning of an expression as a contribution to the meaning of the utterance is complete or we end up in the regress I have just emphasized. This conclusion seems to be fatal for those who argue that truth conditions vary with contexts: near-side pragmatic effects, or contextual contributions, cannot "latch onto" the invariant part, or whatever is thought to constitute the semantic or lower level of a framework. ${ }^{11}$

11 What thereby is shown, too, is that drawing a distinction between semantics and pragmatics requires that the semantic level has to be regarded as significant independently from pragmatics. This is not so if pragmatic effects overrule qua pragmatic effects the contributions of the semantic level. By way of an example, even if one admits that it is possible that the sentence "The lion sleeps tonight" can be used to express the proposition that the woman in the corner is Ginger, for instance by way of an implicature, it cannot be a general principle. For if the role of the semantics is displaced, there is no relatum which corresponds to semantics as the counterpart of pragmatics. In other words, semantics and pragmatics collapse. 
At the beginning of this section, I formulated a dilemma: either near-side pragmatic effects are tied to what represents the semantic level or the distinction represents an ill-founded postulation. As it is with dilemmas, the second horn shares with the first one its problems. If it is assumed that near-side pragmatic effects can be specified independently of any other level of a framework, then their contribution to the semantic level cannot be accounted for. In general, this means that once one of the levels involved in a framework based on a distinction between semantics and pragmatics is taken to be irrelevant, one should not assume a distinction anymore. As a consequence, it does not make sense to speak of a relation between semantics and pragmatics in such a way that it makes sense to identify the fields in question independently of each other. But then it seems that the idea of a theory of interpretation based on such a distinction makes no sense.

\section{Conclusion}

Proponents of the distinction between semantics and pragmatics maintain that we can appeal to either aspect without any need to invoke the other. Indeed, this is exactly how one can disentangle pragmatic and semantic effects. This commitment to what I call the independency condition gives rise to a special version of the problem of the unity of an utterance. In comparing theories which draw a distinction between different levels with Davidson's theory of interpretation, I have emphasized that the former cannot account for the unity. I further believe that this failure indicates the unintelligibility of understanding a sentence as distinct from the way we communicate. The idea that part of an utterance - a sentence as representative for semantics - remains constant and another part the effects on the sentence - varies has proven to be unsuccessful. For either the varying factors are tied to the sentence's level, so there is no essential distinction between semantics and pragmatics. Or, there is a distinction, but the grounds for being effective are opaque.

\section{Acknowledgments}

I would like to thank Gabriele M. Mras and Charles Djordjevic for valuable comments on early versions of this paper. 


\section{References}

Austin, John L. 1962. How to do things with words. Oxford: Clarendon Press.

Bach, Kent. 1999. The semantics pragmatics distinction: What it is and why it matters. In Ken Turner, (ed.), The semantics-pragmatics interface from different points of view, 65-84. Oxford: Elsevier.

Bach, Kent. 2004. Minding the gap. In Claudia Bianchi (ed.), The semantics/pragmatics distinction, 27-43. Stanford: CSLI.

Bezuidenhout, Anne. 2002. Truth-conditional pragmatics. Noûs 36. 105-134.

Cappelen, Herman. 2007. Semantics and pragmatics: Some central issues. In Gerhard Preyer \& Georg Peter (eds.), Context-sensitivity and semantic minimalism, 3-23. Oxford: Oxford University Press.

Cappelen, Herman \& Ernie Lepore. 2005. Insensitive semantics: A defense of semantic minimalism and speech act pluralism. Oxford: Blackwell.

Davidson, Donald. 1967. Truth and meaning. In Donald Davidson, Inquiries into truth and interpretation, 17-36. Oxford: Clarendon Press.

Davidson, Donald. 1970. Semantics for natural languages. In Donald Davidson, Inquiries into truth and interpretation, 55-64. Oxford: Clarendon Press.

Davidson, Donald. 2005. Truth and predication. Cambridge, MA: Belknap Press.

Gaskin, Richard, 2008. The unity of the proposition. New York: Oxford University Press.

Grice, Paul. 1989. Studies in the way of words. Cambridge, MA: Harvard University Press.

Hylton, Peter. 1984. The nature of the proposition and the revolt against idealism. In Peter

Hylton (ed.), Propositions, Functions, and Analysis. Selected essays on Russell's

Philosophy, 9-29. Oxford: Clarendon Press.

Almog, Joseph, Perry, John, Wettstein, Howard \& Kaplan, David (eds.). 1989. Themes from Kaplan. New York: Oxford University Press.

Levinson, Stephen C. 1983. Pragmatics. Cambridge: Cambridge University Press.

Morris, Charles. 1938. Foundations of a theory of signs. In Charles Morris (ed.), Writings on the general theory of signs, 17-72. The Hague and Paris: Mouton.

Recanati, François. 2004. Literal meaning. Cambridge: Cambridge University Press.

Recanati, François. 2001. What is said. Synthese 128(1/2). 75-91.

Recanati, François. 2010. Truth-conditional pragmatics. Oxford: Clarendon Press.

Riegelnik, Stefan (ed.). 2010. Predication and the unity of proposition. Special issue of Conceptus - Journal of Philosophy 96-97.

Russell, Bertrand. [1903]/2010. Principles of mathematics. London \& New York: Routledge Classics.

Stalnaker, Robert C. 1970. Pragmatics. Synthese 22(1/2). 272-289.

Stanley, Jason, King, Jeffrey C. 2007. Semantics, pragmatics, and the role of semantic content. In Stanley, Jason (ed.). Language in Context. Selected Essays, 133-181. New York: Oxford University Press.

Stanley, Jason. 2007. Language in context. Selected essays. New York: Oxford University Press. 